\title{
Associations between dietary inflammatory index and inflammatory markers in the Asklepios Study
}

\author{
Nitin Shivappa ${ }^{1,2}$, James R. Hébert ${ }^{1,2 *}$, Ernst R. Rietzschel ${ }^{3}$, Marc L. De Buyzere ${ }^{3}$, Michel Langlois ${ }^{4}$, \\ Evi Debruyne ${ }^{4}$, Ascensión Marcos ${ }^{5}$ and Inge Huybrechts ${ }^{6,7}$ \\ ${ }^{1}$ Cancer Prevention and Control Program, University of South Carolina, 915 Greene Street, Suite 241, Columbia, \\ SC 29208, USA \\ ${ }^{2}$ Department of Epidemiology and Biostatistics, Arnold School of Public Health, University of South Carolina, \\ Columbia, SC 29208, USA \\ ${ }^{3}$ Department of Cardiovascular Diseases, Ghent University, Ghent, Belgium \\ ${ }^{4}$ Asklepios Core-Lab, Department of Laboratory Medicine, AZ St-Jan, Brugge, Belgium \\ ${ }^{5}$ Department of Metabolism and Nutrition, Institute of Food Science and Technology and Nutrition, Madrid, Spain \\ ${ }^{6}$ Department of Public Health, Ghent University, Ghent, Belgium \\ ${ }^{7}$ Dietary Exposure Assessment Group, International Agency for Research on Cancer, Lyon, France
}

(Submitted 12 June 2014 - Final revision received 19 August 2014 - Accepted 4 November 2014 - First published online 2 February 2015)

\section{Abstract}

Previous research has shown that nutrients and certain food items influence inflammation. However, little is known about the associations between diet, as a whole, and inflammatory markers. In the present study, we examined the ability of a FFQ-derived dietary inflammatory index (DII) to predict inflammation. Data from a Belgian cross-sectional study of 2524 generally healthy subjects (age $35-55$ years) were used. The DII is a population-based, literature-derived dietary index that was developed to predict inflammation and inflammationrelated chronic diseases. The DII was calculated from FFQ-derived dietary information and tested against inflammatory markers, namely C-reactive protein (CRP), IL-6, homocysteine and fibrinogen. Analyses were performed using multivariable logistic regression, adjusting for energy, age, sex, BMI, smoking status, education level, use of non-steroidal anti-inflammatory drugs, blood pressure, use of oral contraceptives, anti-hypertensive therapy, lipid-lowering drugs and physical activity. Multivariable analyses showed significant positive associations between the DII and the inflammatory markers IL-6 (>1.6 pg/ml) (OR 1.19, 95\% CI 1.04, 1.36) and homocysteine $(>15 \mu \mathrm{mol} / \mathrm{l})(\mathrm{OR} 1 \cdot 56,95 \%$ CI $1 \cdot 25,1 \cdot 94)$. No significant associations were observed between the DII and the inflammatory markers CRP and fibrinogen. These results reinforce the fact that diet, as a whole, plays an important role in modifying inflammation.

Key words: Diet: Inflammation: Inflammatory markers: Cytokines: Chronic disease risk

Acute inflammation, a necessary process of the body's natural response to tissue injury, helps to heal wounds and promote tissue regeneration ${ }^{(1-4)}$. A chronic, low-grade inflammatory state results when this process of inflammation is not controlled properly ${ }^{(4)}$. Chronic inflammation has been shown to be associated with cancer ${ }^{(5,6)}$ and $\mathrm{CVD}^{(7-10)}$ such as $\mathrm{CHD}^{(11)}$ and myocardial infarction ${ }^{(10)}$. The major inflammatory markers that are implicated in these chronic diseases are IL- $^{(10)}$, fibrinogen $^{(11)}$, high-sensitivity C-reactive protein (hs-CRP) ${ }^{(11)}$ and leucocyte count ${ }^{(11)}$.

Dietary factors also have been associated with inflammation. The Western-type diet, which is high in red meat, high-fat dairy products and refined grains, is associated with higher levels of CRP, IL-6 and fibrinogen ${ }^{(12,13)}$. In contrast, the Mediterranean diet, which is high in whole grains, fruit and green vegetables, and fish and low in red meat and butter, with moderate alcohol consumption and olive oil intake, is associated with lower levels of inflammation ${ }^{(14)}$ Diets high in fruit and vegetables are associated with lower levels of $\mathrm{CRP}^{(15)}$. Specific nutrients also have been consistently shown to be associated with lower levels of inflammation. These include complex carbohydrates ${ }^{(16)}, n-3$ PUFA $^{(17)}$, fibre $^{(18)}$, moderate alcohol intake ${ }^{(19)}$, vitamin $\mathrm{E}^{(20)}$, vitamin $\mathrm{C}^{(21)}, \beta$-carotene ${ }^{(22)}$ and $\mathrm{Mg}^{(23)}$

The dietary inflammatory index (DII) was developed to provide a means for estimating the overall inflammatory potential of the diet ${ }^{(24,25)}$. The DII is based on an extensive literature search incorporating cell culture, animal and

Abbreviations: CRP, C-reactive protein; DII, dietary inflammatory index; hs-CRP, high-sensitivity C-reactive protein

*Corresponding author: Professor Dr J. R. Hébert, fax +1 803576 5624, email jhebert@sc.edu 
epidemiological studies of the effect of diet on inflammation. DII scoring is not dependent on subjective evaluation of the diet or recommendations of intake. Because it is based on the literature that links diet to inflammation, the DII is not limited to micronutrients and macronutrients, but also incorporates commonly consumed components of the diet including flavonoids, spices and tea. Previously, the DII has been shown to predict CRP levels ${ }^{(25,26)}$. Using the Asklepios Study, we tested the hypothesis that higher DII scores, indicating a more pro-inflammatory diet, are associated with increased systemic inflammation, as shown by increased levels of inflammatory markers.

\section{Methods \\ Study design}

Briefly, the Asklepios Study was a longitudinal populationbased study conducted in Belgium, with baseline data collected in October 2002. The primary objective of the study was to explore the interplay between ageing, diet, cardiovascular haemodynamics and inflammation. A total of 2524 healthy volunteers aged between 35 and 55 years were recruited. Subjects were randomly sampled from the twinned communities of Erpe-Mere and Nieuwerkerken in Flanders, Belgium. Inclusion criteria were as follows: male or female volunteers aged $35-55$ years at study initiation; living in the communities of Erpe-Mere or Nieuwerkerken. Exclusion criteria were as follows: the presence of clinical atherosclerosis; major comorbidity; diabetes mellitus; pregnancy; atrial fibrillation; irregular heart cycle; inability to give informed consent. More details about the inclusion and exclusion criteria used can be found in the methods and baseline characteristics of the Asklepios Study ${ }^{(27)}$.

For the present study, only baseline data on diet, inflammatory markers and covariates were used to perform a cross-sectional analysis. After excluding thirty-seven participants who did not complete the FFQ, there were 2487 subjects with evaluable data, of whom 1200 were men and 1287 were women. Data on demographic characteristics were obtained using a self-administered questionnaire. Anthropometric measurements and blood samples were collected, and the levels of inflammatory markers were determined ${ }^{(27)}$. Basic clinical data assessment and routine biochemical assays were performed as described previously ${ }^{(27)}$. In summary, five markers of inflammation were measured: hs-CRP; leucocyte count; fibrinogen; homocysteine; IL-6.

\section{Dietary intake and dietary inflammatory index}

Participants were asked to complete a semi-quantitative FFQ that included questions on their habitual daily consumption of twenty-five food items during the past year ${ }^{(28)}$. This FFQ was based on an existing FFQ used in this population and on a short FFQ (i.e. sixty items) developed by Willett $^{(29,30)}$. Participants were asked to indicate how often they consumed each item in a list of frequencies (every day; 5-6d/week; 2-4d/week; $1 \mathrm{~d} /$ week; 1-3 times/month; never or less than once a month), and to indicate approximate portion size.

FFQ-derived dietary information was used to calculate DII scores for all of the subjects, as described in detail elsewhere ${ }^{(24,25)}$. Briefly, dietary data for each study participant were first linked to a regionally representative global database that provided a robust estimate of means and standard deviations for each of the food parameters considered (i.e. foods, nutrients and other food components such as flavonoids) ${ }^{(24)}$. A $z$-score was derived by subtracting the 'standard global mean' from the amount reported, and then this value was divided by the standard deviation. To minimise the effect of 'right skewing' (a common occurrence with dietary data), this value was then converted to a centred percentile score, which was then multiplied by the respective inflammatory effect score of the food parameters (derived from a literature review and scoring of 1943 'qualified' articles) to obtain the subject's food parameter-specific DII score. All of the food parameter-specific DII scores were then summed to create the overall DII score for each subject in the study. For the current FFQ, data were available for a total of seventeen food parameters (carbohydrate, protein, total fat, fibre, cholesterol, saturated fat, monounsaturated fat, polyunsaturated fat, n-6 fatty acid, thiamin, riboflavin, vitamin $\mathrm{B}_{12}, \mathrm{Fe}, \mathrm{Mg}, \mathrm{Zn}$, vitamin $\mathrm{A}$ and vitamin $\mathrm{C}$ ). A description of the validation work of the DII score, based on both dietary recalls and a structured questionnaire, the $7 \mathrm{~d}$ dietary recall that is similar to an FFQ, is available elsewhere ${ }^{(26)}$. Thus far, the DII has been found to be associated with inflammatory cytokines, including CRP and IL- $6^{(26,31,32)}$, the glucose intolerance component of the metabolic syndrome, the increased odds of asthma and $\mathrm{FEV}_{1}$ (reduced forced expiratory volume in $1 \mathrm{~min}$ ), inflammatory markers in shift workers, and colorectal, prostate and pancreatic cancers ${ }^{(31-38)}$.

\section{Statistical analyses}

All markers of inflammation were analysed as categorical variables using conventional cut-off points. As recommended by the Centers for Disease Control and Prevention (CDC) and the American Heart Association, we dichotomised hs-CRP at the level of $3 \mathrm{mg} / \mathrm{l}^{(7)}$, categorised homocysteine at the level of $15 \mu \mathrm{mol} / \mathrm{l}^{(39)}$ and fibrinogen at the level of $4.5 \mathrm{~g} / 1$, considering measurements greater than this level as indicative of higher CVD risk. IL-6 was categorised at a detection level of $1.6 \mathrm{pg} / \mathrm{ml}^{(28)}$. As there were no clear cut-off values for leucocyte count, it was not analysed.

All statistical analyses were carried out using the SAS ${ }^{\circledR}$ statistical software package (version 9.3; SAS Institute, Inc.). Comparisons of baseline characteristics by sex were made by $\chi^{2}$ tests for categorical variables and by two-sample $t$ tests for continuous variables. BMI was categorised as normal $\left(<25 \mathrm{~kg} / \mathrm{m}^{2}\right)$, overweight $\left(25-30 \mathrm{~kg} / \mathrm{m}^{2}\right)$ and obese $\left(>30 \mathrm{~kg} / \mathrm{m}^{2}\right)$. Physical activity is expressed as metabolic equivalents (METS). Analyses were carried out using multivariable logistic regression, adjusting for energy, age, sex, BMI, smoking status, education level, use of non-steroidal anti-inflammatory drugs, 
blood pressure, use of oral contraceptives, lipid-lowering drugs, anti-hypertensive therapy and physical activity.

\section{Results}

Table 1 shows the baseline characteristics of the study participants and the mean DII scores for both sexes. Women had lower DII scores than did men $(-1.01 v .090)$, indicating that women consume a more anti-inflammatory diet than men. Women were more educated, less likely to be obese and more likely to be current smokers compared with men. Women had higher CRP levels; however, other inflammatory markers did not differ by sex. Table 2 presents the distribution of characteristics, various food groups and inflammatory markers across the tertiles of the DII. Tertile 3 had a higher number of current smokers and males than did tertile 1. Participants in tertile 3 had a lower consumption of antiinflammatory food groups such as vegetables, fish and fruit, and had a higher consumption of pro-inflammatory foods such as sugar-sweetened soft drinks. Participants in tertile 2 had a higher consumption of meat than those in tertile 1; however, participants in tertile 3 had a lower consumption of meat. Participants in tertile 3 had higher levels of IL-6 and homocysteine.

\section{Analysis of inflammatory markers as categorical variables}

Multivariable-adjusted analysis showed positive associations between the DII and the inflammatory markers IL-6 (OR $1 \cdot 19,95 \%$ CI 1.04, 1.36) and homocysteine (OR 1.56, $95 \%$ CI $1.25,1.94)$. For each unit increase in the DII, the odds of having IL-6 $>1.6 \mathrm{pg} / \mathrm{ml}$ and homocysteine $>15 \mu \mathrm{mol} / \mathrm{l}$ increased by 19 and 56\%, respectively. The DII was not found to be associated with hs-CRP ( $>3 \mathrm{mg} / \mathrm{l})$ and fibrinogen $(>4.5 \mathrm{~g} / \mathrm{l})($ Table 3$)$

\section{Discussion}

The results from the present study indicate that a diet with predominantly pro-inflammatory food parameters such as cholesterol and saturated fat, and relatively poor in anti-inflammatory food parameters such as fruit and vegetables, increased inflammation in the study participants as evidenced by the increased levels of IL-6, homocysteine and

Table 1. Characteristics of the Asklepios Study population and mean dietary inflammatory index (DII) scores

(Number of participants and percentages; mean values and standard deviations; medians and interquartile ranges (IQR))

\begin{tabular}{|c|c|c|c|c|c|}
\hline \multirow[b]{2}{*}{ Characteristics } & \multicolumn{2}{|c|}{$\begin{array}{l}\text { Women } \\
(n 1287)\end{array}$} & \multicolumn{2}{|c|}{ Men (n 1200) } & \multirow[b]{2}{*}{$P^{*}$} \\
\hline & $n$ & $\%$ & $n$ & $\%$ & \\
\hline Age (years) & & & & & 0.40 \\
\hline Mean & \multicolumn{2}{|c|}{45.9} & \multicolumn{2}{|c|}{$46 \cdot 1$} & \\
\hline SD & \multicolumn{2}{|c|}{$6 \cdot 0$} & \multicolumn{2}{|c|}{5.9} & \\
\hline \multicolumn{5}{|l|}{ Education (years) $\dagger$} & $<0.0001$ \\
\hline University & 71 & $5 \cdot 7$ & 154 & $13 \cdot 3$ & \\
\hline Beyond secondary & 360 & 28.9 & 312 & $26 \cdot 9$ & \\
\hline Secondary and below & 813 & 65.4 & 693 & $59 \cdot 8$ & \\
\hline \multicolumn{5}{|l|}{ BMI $\left(\mathrm{kg} / \mathrm{m}^{2}\right) \dagger$} & $<0.0001$ \\
\hline Normal $\left(<25 \mathrm{~kg} / \mathrm{m}^{2}\right)$ & 755 & $59 \cdot 2$ & 419 & $35 \cdot 0$ & \\
\hline Overweight $\left(25-30 \mathrm{~kg} / \mathrm{m}^{2}\right)$ & 356 & $27 \cdot 9$ & 575 & $48 \cdot 0$ & \\
\hline Obese $\left(>30 \mathrm{~kg} / \mathrm{m}^{2}\right)$ & 165 & $12 \cdot 9$ & 204 & $17 \cdot 0$ & \\
\hline \multicolumn{5}{|l|}{ Smoking status $†$} & $<0.0001$ \\
\hline Non-smoker & 770 & 50.5 & 282 & $41 \cdot 6$ & \\
\hline Ex-smoker & 279 & 21.9 & 418 & 34.9 & \\
\hline Current smoker & 227 & $17 \cdot 8$ & 490 & 23.5 & \\
\hline hs-CRP (mg/l) & & & & & $<0.0001$ \\
\hline Median & \multicolumn{2}{|c|}{1.4} & \multicolumn{2}{|c|}{1.0} & \\
\hline IQR & \multicolumn{2}{|c|}{$0.6,3.3$} & \multicolumn{2}{|c|}{$0.5,1.9$} & \\
\hline IL-6 > $1.6 \mathrm{pg} / \mathrm{ml}$ (yes) (\%) & \multicolumn{2}{|c|}{24.5} & \multicolumn{2}{|c|}{$26 \cdot 5$} & 0.25 \\
\hline Leucocyte count $\left(\times 10^{3} / \mu \mathrm{l}\right)$ & & & & & 0.01 \\
\hline Median & \multicolumn{2}{|c|}{$6 \cdot 6$} & \multicolumn{2}{|c|}{$6 \cdot 4$} & \\
\hline IQR & \multicolumn{2}{|c|}{$5 \cdot 4,7 \cdot 7$} & \multicolumn{2}{|c|}{$5 \cdot 2,7 \cdot 4$} & \\
\hline Homocysteine $(\mu \mathrm{mol} / \mathrm{l})$ & \multirow{2}{*}{\multicolumn{2}{|c|}{9.4}} & \multirow{2}{*}{\multicolumn{2}{|c|}{$11 \cdot 0$}} & $<0.0001$ \\
\hline Median & & & & & \\
\hline IQR & \multicolumn{2}{|c|}{$8 \cdot 0,11 \cdot 1$} & \multicolumn{2}{|c|}{$9 \cdot 4,12 \cdot 8$} & \\
\hline Fibrinogen (g/l) & \multirow{3}{*}{\multicolumn{2}{|c|}{$\begin{array}{c}3 \cdot 27 \\
2 \cdot 91,3 \cdot 70\end{array}$}} & & & $<0.0001$ \\
\hline Median & & & \multirow{2}{*}{\multicolumn{2}{|c|}{$\begin{array}{c}3.06 \\
2 \cdot 74,3 \cdot 38\end{array}$}} & \\
\hline IQR & & & & & \\
\hline DIl score & -1.01 & 0.8 & -0.90 & 0.7 & 0.003 \\
\hline
\end{tabular}

hs-CRP, high-sensitivity C-reactive protein

*ANOVA was used for continuous variables and $\chi^{2}$ test for categorical variables.

†The sum does not add up to the total because of some missing values. 
Table 2. Description of population characteristics across the tertiles of the dietary inflammatory index

(Number of participants and percentages*; mean values and standard deviations $†$ )

\begin{tabular}{|c|c|c|c|c|c|c|c|}
\hline \multirow[b]{2}{*}{ Characteristics } & \multicolumn{2}{|c|}{$\begin{array}{l}\text { Tertile } 1 \\
(<-1.38)\end{array}$} & \multicolumn{2}{|c|}{$\begin{array}{c}\text { Tertile } 2 \\
(-1.38 \text { to } \\
-0.70)\end{array}$} & \multicolumn{2}{|c|}{$\begin{array}{c}\text { Tertile } 3 \\
(>-0.70)\end{array}$} & \multirow[b]{2}{*}{$P \ddagger$} \\
\hline & $n$ & $\%$ & $n$ & $\%$ & $n$ & $\%$ & \\
\hline Age (years) & \multirow{2}{*}{\multicolumn{2}{|c|}{$46 \cdot 1$}} & & & & & 0.79 \\
\hline Mean & & & \multicolumn{2}{|c|}{45.6} & \multicolumn{2}{|c|}{$46 \cdot 2$} & \\
\hline SD & \multicolumn{2}{|c|}{6.0} & \multicolumn{2}{|c|}{$6 \cdot 0$} & \multicolumn{2}{|c|}{5.9} & \\
\hline BMI $\left(\mathrm{kg} / \mathrm{m}^{2}\right)$ & & & & & & & 0.83 \\
\hline Mean & \multicolumn{2}{|c|}{$25 \cdot 6$} & \multicolumn{2}{|c|}{$25 \cdot 9$} & \multicolumn{2}{|c|}{$25 \cdot 6$} & \\
\hline SD & \multicolumn{2}{|c|}{$4 \cdot 1$} & \multicolumn{2}{|c|}{$4 \cdot 2$} & \multicolumn{2}{|c|}{4.3} & \\
\hline \multicolumn{7}{|l|}{ Smoking status } & $<0.0001$ \\
\hline Non-smoker & 441 & 53.6 & 421 & $51 \cdot 1$ & 406 & $49 \cdot 1$ & \\
\hline Ex-smoker & 256 & $31 \cdot 1$ & 243 & 29.5 & 198 & 23.9 & \\
\hline Current smoker & 126 & $15 \cdot 3$ & 160 & $19 \cdot 4$ & 223 & $27 \cdot 0$ & \\
\hline Sex & & & & & & & 0.0004 \\
\hline Females & 471 & $57 \cdot 2$ & 404 & $49 \cdot 0$ & 401 & 48.5 & \\
\hline Males & 352 & $42 \cdot 8$ & 420 & $51 \cdot 0$ & 426 & 51.5 & \\
\hline \multicolumn{8}{|l|}{ Food group intake } \\
\hline Vegetables $(\mathrm{g} / \mathrm{d})$ & \multirow{2}{*}{\multicolumn{2}{|c|}{229.4}} & & & & & $<0.0001$ \\
\hline Mean & & & \multicolumn{2}{|c|}{183.7} & \multicolumn{2}{|c|}{$113 \cdot 2$} & \\
\hline SD & & & & & & & \\
\hline Fish and fish products $(\mathrm{g} / \mathrm{d})$ & & & & & & & $<0.0001$ \\
\hline Mean & & & & & & & \\
\hline SD & & & & & & & \\
\hline Fruit $(g / d)$ & & & & & & & $<0.0001$ \\
\hline Mean & & & & & & & \\
\hline $\mathrm{SD}$ & & & & & & & \\
\hline Sugared drinks $(\mathrm{ml} / \mathrm{d})$ & & & & & & & 0.01 \\
\hline Mean & & & & & & & \\
\hline$S D$ & & & & & & & \\
\hline Meat $(\mathrm{g} / \mathrm{d})$ & & & & & & & $<0.0001$ \\
\hline Mean & & & & & & & \\
\hline SD & & & & & & & \\
\hline Inflammatory markers & & & & & & & \\
\hline $\mathrm{CRP}(>3 \mathrm{mg} / \mathrm{l})$ & & & & & & & 0.83 \\
\hline High & 173 & 21.0 & 169 & $20 \cdot 5$ & 164 & $19 \cdot 8$ & \\
\hline Low & 650 & $79 \cdot 0$ & 655 & 79.5 & 663 & $80 \cdot 2$ & \\
\hline IL-6 & & & & & & & 0.30 \\
\hline$>1.5 \mathrm{pg} / \mathrm{ml}$ & 194 & 23.6 & 221 & $26 \cdot 8$ & 214 & 25.9 & \\
\hline$\leq 1.5 \mathrm{pg} / \mathrm{ml}$ & 629 & $76 \cdot 4$ & 603 & $73 \cdot 2$ & 613 & $74 \cdot 1$ & \\
\hline Homocysteine $(>15 \mu \mathrm{mol} / \mathrm{l})$ & & & & & & & 0.002 \\
\hline High & 44 & $5 \cdot 3$ & 67 & $8 \cdot 1$ & 83 & $10 \cdot 0$ & \\
\hline Low & 779 & $95 \cdot 7$ & 757 & 91.9 & 744 & $90 \cdot 0$ & \\
\hline Leucocyte count $\left(\times 10^{3} / \mu \mathrm{l}\right)$ & & & & & & & 0.02 \\
\hline Mean & & & & & & & \\
\hline SD & & & & & & & \\
\hline Fibrinogen (g/l) & & & & & & & 0.57 \\
\hline Mean & & & & & & & \\
\hline SD & & & & & & & \\
\hline
\end{tabular}

${ }^{*}$ Categorical variables.

†Continuous variables.

$\ddagger$ The $t$ test was used for continuous variables and $\chi^{2}$ test for categorical variables.

leucocyte count. Overall, the results of the present study are consistent with the hypothesis that diet modulates inflammation. The inference is that through this process of modulating inflammation, there is an effect on chronic diseases such as several cancers and CVD.

Previous results from the Asklepios Study have shown that adherence to Flemish food-based dietary guidelines results in lower inflammation ${ }^{(28)}$. The present results are in accordance with the findings from previous studies that have found a relationship between diet and inflammatory markers ${ }^{(40-44)}$.
We found an independent positive association between adherence to the pro-inflammatory diet (increasing DII score) and the inflammatory markers IL-6, and homocysteine, but not CRP and fibrinogen. This is consistent with the observations from previous studies showing that IL- 6 is a more sensitive indicator of CVD such as atherosclerosis and cardiovascular risk than are hs-CRP and fibrinogen ${ }^{(10,45)}$. IL-6 promotes atherosclerosis, by stimulating the endothelial synthesis of cellular adhesion molecules, procoagulant effects, and stimulation of hepatic hs-CRP synthesis ${ }^{(10,45)}$. Leucocytosis 
Table 3. Associations between the dietary inflammatory index and inflammatory markers as categorical variables

\begin{tabular}{lccccc}
\hline Categorical variables & High/normal & OR $^{\star}$ & $95 \% \mathrm{Cl}$ & OR $\dagger$ & $95 \% \mathrm{Cl}$ \\
\hline hs-CRP $(>3 \mathrm{mg} / \mathrm{l})$ & $506 / 1958$ & 0.94 & $0.82,1.07$ & 1.03 & $0.86,1.17$ \\
IL-6 $(>1.6 \mathrm{pg} / \mathrm{l})$ & $629 / 1845$ & 1.12 & $1.00,1.30$ & 1.19 & $1.04,1.36$ \\
Homocysteine $(>15 \mu \mathrm{mol} / \mathrm{l})$ & $194 / 2280$ & 1.50 & $1.25,1.81$ & 1.56 & $1.25,1.94$ \\
Fibrinogen $(>4.5 \mathrm{~g} / \mathrm{l})$ & $80 / 2394$ & 1.15 & $0.86,1.54$ & 1.08 & $0.78,1.48$ \\
\hline
\end{tabular}

hs-CRP, high-sensitivity C-reactive protein.

${ }^{*}$ Adjusted for age.

† Adjusted for energy, age, sex, BMI, smoking status, education level, use of non-steroidal anti-inflammatory drugs, blood pressure, use of oral contraceptives, anti-hypertensive therapy, lipid-lowering drugs and physical activity.

has consistently been shown to be an independent risk factor and prognostic indicator of future cardiovascular outcomes, regardless of disease status. Mechanisms that link leucocytosis to CHD occur through the mediation of inflammation, resulting in proteolytic and oxidative damage to the endothelial cell that plug the microvasculature, induce hypercoagulability and promote infarct expansion ${ }^{(46)}$. Hyperhomocysteinaemia is also known to play an important role in the causation of $\mathrm{CVD}^{(47)}$. The results from animal and in vitro experimental studies have shown blood homocysteine levels to be positively associated with vascular and platelet damage ${ }^{(47-49)}$. Homocysteine is not a commonly studied inflammatory marker; however, previous research ${ }^{(50,51)}$ has shown that homocysteine can be considered as an inflammatory marker and higher levels of homocysteine tend to be strongly positively correlated with inflammatory markers related to an increased risk of CVD.

The present study has several limitations. Although the FFQ is typically used to investigate habitual (long-term) dietary intakes in large-scale surveys, its closed structure with limited response options limits its ability to detect between-person variations; this is in contrast to open-ended methods such as food records or $24 \mathrm{~h}$ dietary recalls. In addition, the FFQ relies on the respondents' memory and their capabilities to interpret those questions on frequency and quantity of consumption. However, the important strengths of the FFQ are its low respondent burden and cost, and the fact that, at least theoretically, it gives information about the respondents' usual or habitual dietary intakes ${ }^{(30)}$. Another limitation of this design is that no cause-effect relationships can be inferred from these cross-sectional data, and a single measure of diet notably reduces at least the precision (and, probably, the accuracy) of our estimates. Also, it is possible that multiple testing may have resulted in chance associations being declared significant.

In the DII validation study ${ }^{(26)}$, sensitivity analysis was conducted to compare DII scores calculated from multiple (up to $15 /$ person) $24 \mathrm{~h}$ dietary recalls with those calculated from $7 \mathrm{~d}$ dietary recalls (providing data on twenty-eight food parameters). We found that the ability to predict CRP was not attenuated when using the more limited list available with the $7 \mathrm{~d}$ dietary recalls ${ }^{(26)}$. In the present study, the DII was calculated using the data on just seventeen food parameters derived from the FFQ, the shortest list on which we have published thus far. This could explain the absence of an association between the DII and CRP in the present study. However, despite the large reduction in the number of food parameters, we still were able to predict various inflammatory markers successfully.

\section{Conclusion}

Chronic inflammation appears to play a key role in the development of CVD and certain cancers. The results from the present study suggest that eating a diet high in sugar, saturated fat and other pro-inflammatory foods promote inflammation, which may increase the risk of a variety of chronic diseases. The next logical step would be to use the DII to predict CVD outcomes, such as atherosclerosis, and indicators of CVD including intimal thickening, plaque formation and cardiac output in the Asklepios Study.

\section{Acknowledgements}

The authors thank the Asklepios Study staff for assistance in the data preparation. The authors acknowledge all the participants from the Asklepios Study who voluntarily contributed to the study.

The Asklepios Study was partly funded by an FWO research grant (G.0427.03). J. R. H. was supported by an Established Investigator Award in Cancer Prevention and Control from the Cancer Training Branch of the US National Cancer Institute (NCI) (K05 CA136975). This research received no other specific grant from any funding agency, commercial or notfor-profit sectors. The FWO and NCI had no role in the design and analysis of the study or in the writing of this article.

The authors' contributions are as follows: N. S. was involved in the calculation of the DII in the dataset, performed all the analyses and drafted the first version of the manuscript; I. H. helped with the analyses, data acquisition, interpretation of the data, and critical revision of the manuscript; E. R. R., M. L. D. B., M. L., E. D. and A. M. contributed to the data interpretation and drafting of the manuscript; J. R. H. provided expertise and oversight throughout the process. All the authors approved the final version.

All authors declare that there is no conflict of interest. 


\section{References}

1. Keibel A, Singh V \& Sharma MC (2009) Inflammation, microenvironment, and the immune system in cancer progression. Curr Pharm Des 15, 1949-1955.

2. Pan MH, Lai CS, Dushenkov S, et al. (2009) Modulation of inflammatory genes by natural dietary bioactive compounds. J Agric Food Chem 57, 4467-4477.

3. Thun MJ, Henley SJ \& Gansler T (2004) Inflammation and cancer: an epidemiological perspective. Novartis Found Symp 256, 6-21, discussion 2-8, 49-52, 266-269.

4. Warnberg J, Gomez-Martinez S, Romeo J, et al. (2009) Nutrition, inflammation, and cognitive function. Ann $N Y$ Acad Sci 1153, 164-175.

5. Terzić J, Grivennikov S, Karin E, et al. (2010) Inflammation and colon cancer. Gastroenterology 138, 2101.e5-2114.e5.

6. Elinav E, Nowarski R, Thaiss CA, et al. (2013) Inflammationinduced cancer: crosstalk between tumours, immune cells and microorganisms. Nat Rev Cancer 13, 759-771.

7. Pearson TA, Mensah GA, Alexander RW, et al. (2003) Markers of inflammation and cardiovascular disease: application to clinical and public health practice: a statement for healthcare professionals from the Centers for Disease Control and Prevention and the American Heart Association. Circulation 107, 499-511.

8. Ridker PM, Rifai N, Rose L, et al. (2002) Comparison of C-reactive protein and low-density lipoprotein cholesterol levels in the prediction of first cardiovascular events. $N$ Engl $J$ Med 347, 1557-1565.

9. Blake GJ \& Ridker PM (2002) Inflammatory bio-markers and cardiovascular risk prediction. J Intern Med 252, 283-294.

10. Ridker PM, Rifai N, Stampfer MJ, et al. (2000) Plasma concentration of interleukin- 6 and the risk of future myocardial infarction among apparently healthy men. Circulation 101, 1767-1772.

11. Danesh J, Collins R, Appleby P, et al. (1998) Association of fibrinogen, C-reactive protein, albumin, or leukocyte count with coronary heart disease: meta-analyses of prospective studies. JAMA 279, 1477-1482.

12. Johansson-Persson A, Ulmius M, Cloetens L, et al. (2014) A high intake of dietary fiber influences C-reactive protein and fibrinogen, but not glucose and lipid metabolism, in mildly hypercholesterolemic subjects. Eur J Nutr 53, 39-48.

13. King DE, Egan BM \& Geesey ME (2003) Relation of dietary fat and fiber to elevation of C-reactive protein (erratum appears in Am J Cardiol 2004, 93, 812). Am J Cardiol 92, 1335-1339.

14. Estruch R, Martinez-Gonzalez MA, Corella D, et al. (2006) Effects of a Mediterranean-style diet on cardiovascular risk factors: a randomized trial. Ann Intern Med 145, 1-11.

15. Esmaillzadeh A, Kimiaga M, Mehrabi Y, et al. (2006) Fruit and vegetable intakes, $\mathrm{C}$-reactive protein, and the metabolic syndrome. Am J Clin Nutr 84, 1489-1497.

16. Kitabchi AE, McDaniel KA, Wan JY, et al. (2013) Effects of high-protein versus high-carbohydrate diets on markers of $\beta$-cell function, oxidative stress, lipid peroxidation, proinflammatory cytokines, and adipokines in obese, premenopausal women without diabetes: a randomized controlled trial. Diabetes Care 36, 1919-1925.

17. Ferrucci L, Cherubini A, Bandinelli S, et al. (2006) Relationship of plasma polyunsaturated fatty acids to circulating inflammatory markers (see comment). J Clin Endocrinol Metab 91, 439-446.

18. Ma Y, Griffith JA, Chasan-Taber L, et al. (2006) Association between dietary fiber and serum C-reactive protein. $A m \mathrm{~J}$ Clin Nutr 83, 760-766.
19. Avellone G, Di Garbo V, Campisi D, et al. (2006) Effects of moderate Sicilian red wine consumption on inflammatory biomarkers of atherosclerosis. Eur J Clin Nutr 60, 41-47.

20. Bertran N, Camps J, Fernandez-Ballart J, et al. (2005) Diet and lifestyle are associated with serum C-reactive protein concentrations in a population-based study. J Lab Clin Med 145, 41-46.

21. Wannamethee SG, Lowe GD, Rumley A, et al. (2006) Associations of vitamin $\mathrm{C}$ status, fruit and vegetable intakes, and markers of inflammation and hemostasis. Am J Clin Nutr 83, 567-574, quiz 726-727.

22. Erlinger TP, Guallar E, Miller ER 3rd, et al. (2001) Relationship between systemic markers of inflammation and serum $\beta$-carotene levels. Arch Intern Med 161, 1903-1908.

23. King DE, Mainous AG 3rd, Geesey ME, et al. (2005) Dietary magnesium and C-reactive protein levels. J Am Coll Nutr 24, $166-171$.

24. Shivappa N, Steck SE, Hurley T, et al. (2014) Designing and developing a literature-derived, population-based dietary inflammatory index. Public Health Nutr 17, 1689-1696.

25. Cavicchia PP, Steck SE, Hurley TG, et al. (2009) A new dietary inflammatory index predicts interval changes in high-sensitivity C-reactive protein. J Nutr 139, 2365-2372.

26. Shivappa N, Steck SE, Hurley TG, et al. (2014) A populationbased dietary inflammatory index predicts levels of C-reactive protein in the Seasonal Variation of Blood Cholesterol Study (SEASONS). Public Health Nutr 17, $1825-1833$

27. Rietzschel ER, De Buyzere ML, Bekaert S, et al. (2007) Rationale, design, methods and baseline characteristics of the Asklepios Study. Eur J Cardiovasc Prev Rehabil 14, 179-191.

28. Hoebeeck LI, Rietzschel ER, Langlois M, et al. (2011) The relationship between diet and subclinical atherosclerosis: results from the Asklepios Study. Eur J Clin Nutr 65 , 606-613.

29. Cade J, Thompson R, Burley V, et al. (2002) Development, validation and utilisation of food-frequency questionnaires - a review. Public Health Nutr 5, 567-587.

30. Willett WC (1998) Nutritional Epidemiology. New York: Oxford University Press.

31. Wirth MD, Burch J, Shivappa N, et al. (2014) Association of a dietary inflammatory index with inflammatory indices and metabolic syndrome among police officers. J Occup Environ Med 56, 986-989.

32. Wood L, Shivappa N, Berthon BS, et al. (2015) Dietary inflammatory index is related to asthma risk, lung function and systemic inflammation in asthma. Clin Exp Allergy $\mathbf{4 5}$, $177-183$.

33. Wirth MD, Burch J, Shivappa N, et al. (2014) Dietary inflammatory index scores differ by shift work status: NHANES 2005 to 2010. J Occup Environ Med 56, 145-148.

34. Shivappa N, Prizment AE, Blair CK, et al. (2014) Dietary Inflammatory Index (DII) and risk of colorectal cancer in Iowa Women's Health Study. Cancer Epidemiol Biomarkers Prev 23, 2383-2392.

35. Zamora-Ros R, Shivappa N, Steck SE, et al. (2015) Dietary inflammatory index and inflammatory gene interactions in relation to colorectal cancer risk in the Bellvitge colorectal cancer case-control study. Genes Nutr 10, 447.

36. Tabung F, Steck S, Ma Y, et al. (2014) The association between dietary inflammatory index and risk of colorectal cancer among postmenopausal women: results from 
the Women's Health Initiative. Cancer Causes Control (epublication ahead of print version 31 December 2014).

37. Shivappa N, Bosetti C, Zucchetto A, et al. (2014) Association between dietary inflammatory index and prostate cancer among Italian men. Br J Nutr (epublication ahead of print version 17 November 2014).

38. Shivappa N, Bosetti C, Zucchetto A, et al. (2014) Dietary inflammatory index and risk of pancreatic cancer in an Italian case-control study. Br J Nutr (epublication ahead of print version 17 December 2014).

39. Welch GN \& Loscalzo J (1998) Homocysteine and atherothrombosis. N Engl J Med 338, 1042-1050.

40. Dai J, Miller AH, Bremner JD, et al. (2008) Adherence to the Mediterranean diet is inversely associated with circulating interleukin-6 among middle-aged men: a twin study. Circulation 117, 169-175.

41. Ahluwalia N, Andreeva VA, Kesse-Guyot E, et al. (2013) Dietary patterns, inflammation and the metabolic syndrome. Diabetes Metab 39, 99-110.

42. Baer DJ, Judd JT, Clevidence BA, et al. (2004) Dietary fatty acids affect plasma markers of inflammation in healthy men fed controlled diets: a randomized crossover study. Am J Clin Nutr 79, 969-973.

43. Boynton A, Neuhouser ML, Wener MH, et al. (2007) Associations between healthy eating patterns and immune function or inflammation in overweight or obese postmenopausal women. Am J Clin Nutr 86, 1445-1455.

44. Chrysohoou C, Panagiotakos DB, Pitsavos C, et al. (2004) Adherence to the Mediterranean diet attenuates inflammation and coagulation process in healthy adults: The ATTICA Study. J Am Coll Cardiol 44, 152-158.

45. Cesari M, Penninx BWJH, Newman AB, et al. (2003) Inflammatory markers and onset of cardiovascular events: results from the Health ABC study. Circulation 108, 2317-2322.

46. Madjid M, Awan I, Willerson JT, et al. (2004) Leukocyte count and coronary heart disease: implications for risk assessment. J Am Coll Cardiol 44, 1945-1956.

47. Refsum H, Ueland PM, Nygård $\mathrm{O}$, et al. (1998) Homocysteine and cardiovascular disease. Annu Rev Med 49, 31-62.

48. Harker LA, Ross R, Slichter SJ, et al. (1976) Homocysteineinduced arteriosclerosis. The role of endothelial cell injury and platelet response in its genesis. J Clin Invest 58, 731-741.

49. Harker LA, Slichter SJ, Scott CR, et al. (1974) Homocysteinemia. $N$ Engl J Med 291, 537-543.

50. Oudi ME, Aouni Z, Mazigh C, et al. (2010) Homocysteine and markers of inflammation in acute coronary syndrome. Exp Clin Cardiol 15, e25-e28.

51. Wu JT (2008) Circulating homocysteine is an inflammation marker and a risk factor of life-threatening inflammatory diseases. J Biomed Lab Sci 19, 107-112. 